\title{
Prognostic prediction across a gradient of total tumor volume in patients with hepatocellular carcinoma undergoing locoregional therapy
}

\author{
Teh I Huo ${ }^{1,4^{*}+}$, Chia Y Hsu ${ }^{4,6+}$, Yi H Huang ${ }^{2,4}$, Chien W Su ${ }^{3,4}$, Han C Lin ${ }^{3,4}$, Rheun C Lee, ${ }^{3,5}$, Yi Y Chiou,
} Jen H Chiang ${ }^{3,5}$, Pui C Lee ${ }^{4}$, Shou D Lee Le, $^{3,4}$

\begin{abstract}
Background: The size and number of tumors are important prognostic indicators for hepatocellular carcinoma (HCC). However, it is difficult to assess the prognosis for patients with a variable number and size of tumors. By combining these two factors, we investigated the role and prognostic accuracy of total tumor volume (TTV) for HCC.

Methods: A total of 786 patients undergoing locoregional therapy (transarterial chemoembolization, percutaneous radiofrequency ablation and acetic acid or ethanol injection) for HCC were prospectively evaluated.

Results: The mean and median TTV was $177 \mathrm{~cm}^{3}$ (range, $0.1-3,591 \mathrm{~cm}^{3}$ ) and $21 \mathrm{~cm}^{3}$, respectively. Of all, 38\%, 29\%, $15 \%, 7 \%$ and $11 \%$ of patients had TTV of $<10 \mathrm{~cm}^{3}, 10-50 \mathrm{~cm}^{3}, 50-200 \mathrm{~cm}^{3}, 200-500 \mathrm{~cm}^{3}$ and $>500 \mathrm{~cm}^{3}$,

respectively. TTV was significantly larger in patients with higher serum $\alpha$-fetoprotein (AFP) levels or with vascular invasion. The Child-Turcotte-Pugh score, performance status, vascular invasion, AFP level and TTV were significant independent prognostic predictors in the Cox proportional hazards model. After adjustment, patients with TTV 50$200 \mathrm{~cm}^{3}$ (relative risk [RR]: 1.74, $p=0.009$ ), 200-500 $\mathrm{cm}^{3}$ (RR: $2.15, p=0.006$ ) and $>500 \mathrm{~cm}^{3}$ (RR: $3.92, p<0.001$ ) had a significantly increased mortality risk in comparison to patients with TTV $<10 \mathrm{~cm}^{3}$.

Conclusions: TTV is a feasible prognostic predictor across a wide gradient and can be used to predict the mortality risk of HCC. Selecting appropriate cutoffs of TV may help refine the design of cancer staging system and treatment planning. Future clinical trials of HCC may include this parameter for mortality risk stratification.
\end{abstract}

\section{Background}

Hepatocellular carcinoma (HCC) is one of the most common malignant tumors in the world [1,2]. The prognosis for patients with HCC is often very poor. Among the reported prognostic predictors for HCC, the size and number of tumor nodule, which represent tumor burden, are frequently associated with the aggressiveness of $\mathrm{HCC}$ and are of prime importance in determining the clinical outcome of these patients [3-6]. The size and number of tumor or the extent of tumor involvement have also been included into the staging systems for HCC [7]. In addition, the selection of treatment

\footnotetext{
* Correspondence: tihuo@vghtpe.gov.tw

+ Contributed equally

'Institute of Pharmacology, National Yang-Ming University School of

Medicine, Taipei, Taiwan

Full list of author information is available at the end of the article
}

modality for HCC is also highly dependent on the number and size of tumor nodule. For instance, the Milan criteria are widely accepted standards for HCC patients undergoing liver transplantation [8-10], whereas patients undergoing partial hepatectomy usually have a maximal tumor number of two or three. For patients undergoing percutaneous ethanol or acetic acid injection or radiofrequency ablation, the largest size of tumor is usually set at $3 \mathrm{~cm}$ and the number of tumor nodule usually does not exceed $3[11,12]$. However, for patients beyond these criteria, the treatment selection may widely vary and the prognostic prediction may become quite difficult. A major reason for this uncertainty and heterogeneity in cancer therapy is that a single determinant representing tumor burden has not yet been specifically defined. For example, the prognosis for a patient with a

\section{Biomed Central}


single $6 \mathrm{~cm}$-sized HCC may not be the same for a patient with 3 nodules with a tumor diameter of 4,3 and $2 \mathrm{~cm}$ for each nodule. As such, it is difficult to assess the prognosis for patients with a variable number and size of tumor nodules, and this difficulty may make the application of the currently used prognostic models for HCC less practical and clinically feasible. The concept of using total tumor volume (TTV) to represent tumor burden has been proposed by independent study groups $[13,14]$. By combining the factor of size and number of tumor nodule, we aimed to define the tumor burden by using TTV in assessing the long-term outcome of patients with HCC. In this study, we have investigated the feasibility of TTV, its association with other clinical parameters and its predictive accuracy in patients with HCC undergoing locoregional therapy.

\section{Methods}

\section{Patients and diagnosis}

Patients with newly diagnosed HCC in our hospital were evaluated since April 2002. The clinical parameters in these patients were prospectively assessed and recorded. The diagnosis of HCC was histologically verified by needle biopsy, or based on the findings of typical radiological features in at least two image examinations including ultrasound, contrast-enhanced dynamic computed tomography $(\mathrm{CT})$, magnetic resonance imaging and hepatic angiography, or by a single positive imaging technique associated with serum $\alpha$-fetoprotein (AFP) level $>400 \mathrm{ng} / \mathrm{mL}[15,16]$. The underlying etiology of liver disease was attributed to hepatitis B virus (HBV) infection if patients were seropositive for hepatitis B surface antigen (HBsAg, RIA kits, Abbott Laboratories, North Chicago, IL, USA) and attributed to hepatitis C virus $(\mathrm{HCV})$ infection if patients were seropositive for an antibody against $\mathrm{HCV}$ by a second-generation enzyme immunoassay (Abbott Laboratories, IL). The performance status was evaluated using the Eastern Cooperative Oncology Group (ECOG) performance scale: 0 (asymptomatic) to 4 (confined to bed). The model for end-stage liver disease (MELD) score and Child-Turcotte-Pugh (CTP) score were used to estimate the severity of liver cirrhosis according to previous reports [17-20]. The MELD score $=9.57 \times \log _{\mathrm{e}}($ creatinine $\mathrm{mg} / \mathrm{dL})+3.78 \times \log _{\mathrm{e}}$ (bilirubin $\left.\mathrm{mg} / \mathrm{dL}\right)+11.2 \times$ $\log _{\mathrm{e}}$ (international normalized ratio of prothrombin time $)+6.43$. Minimal values were set to 1.0 for calculation purposes. The maximal serum creatinine level considered within the MELD score equation was $4.0 \mathrm{mg} / \mathrm{dL}$. The CTP classification was based on serum levels of albumin and bilirubin, prothrombin time prolongation, and the severity of ascites and encephalopathy. The Cancer of the Liver Italian Program (CLIP) was used as the staging systems for HCC [7]. The presence of ascites or vascular invasion by the tumors, and the size and number of the each tumor nodule were determined and measured by the contrast-enhanced dynamic CT scan. The volume of a tumor nodule was calculated by using the following mathematical equation:

$$
\begin{aligned}
& \text { Tumor volume }\left(\mathrm{cm}^{3}\right)=4 / 3 \times 3.14 \times \\
& (\text { maximum radius of the tumor nodule in } \mathrm{cm})^{3}
\end{aligned}
$$

TTV was the sum of the tumor volumes of every nodule:

$$
\begin{aligned}
& \operatorname{TTV}\left(\mathrm{cm}^{3}\right)=\text { Tumor volume of } \\
& (\text { tumor nodule } 1+\text { tumor nodule } 2+\ldots \ldots+\text { tumor nodule } \mathrm{N})
\end{aligned}
$$

\section{Treatment}

All patients with a diagnosis of $\mathrm{HCC}$ and admitted to our hospital would undergo initial evaluation for the possibility of surgical resection. For patients with unresectable lesions, curative or palliative locoregional therapy including transarterial chemoembolization (TACE), percutaneous acetic or ethanol acid injection (PAI, PEI), or radiofrequency ablation (RFA) was performed depending on the size and number of tumor nodules. The selection of treatment modality and the details of treatment procedure have been described in our previous studies [6,21-23]. Typically, percutaneous ablation therapies were administered to patients with small $(<3 \mathrm{~cm})$ tumor nodule and lesions no more than three. TACE was indicated for patients with intermediate-sized tumor or multi-nodular lesions. Malignant ascites, main portal vein thrombosis by tumor invasion, or extrahepatic tumoral spread indicated advanced cancer stage and were contraindications for any forms of locoregional therapy. Patients with clinical signs of viable or recurrent tumors after treatment were re-evaluated and retreated using the same or different treatment modality. This study has been approved by the Institutional Review Board of our hospital and complies with the standards of Declaration of Helsinki and current ethical guidelines.

\section{Statistical analysis}

The Chi-squared test or Fisher's exact test was used for categorical data, and the Mann-Whitney ranked sum test was used for continuous data. The Kruskal-Wallis test was used for the comparison across three or more groups. Factors that may be associated with the survival including age, gender, etiology of cirrhosis, CTP score, MELD score, alanine aminotransferase (ALT), aspartate aminotransferase (AST), presence of ascites or vascular invasion, serum AFP level, ECOG performance status 
and TTV, were included in the univariate survival analysis. TTV was further categorized into five groups, $<10 \mathrm{~cm}^{3}, 10-50 \mathrm{~cm}^{3}, 50-200 \mathrm{~cm}^{3}, 200-500 \mathrm{~cm}^{3}$ and $>500 \mathrm{~cm}^{3}$, to determine its prognostic ability for outcome prediction. Survival analysis between different groups of patients was performed by using the Kaplan-Meir method. The significance and relative risk (RR) of the prognostic factors predictive of the survival in HCC patients were determined and adjusted by using the multivariable Cox proportional hazards model. The adjusted relative risks with $95 \%$ confidence intervals (CI) were derived to assess the magnitude of the association between various predictors and the risk or mortality. The discriminatory ability of different staging system was examined by using the Cox proportional hazards model, and the consequences of the Cox model were expressed with the Akaike information criterion (AIC), which reveals how the staging systems affected the dependent variable (patient survival) and represents an overall assessment of a certain staging system $[24,25]$. The lower the AIC, the more explanatory and informative the model is [26]. Statistical significance levels were determined by 2 -tailed tests. A p value $<0.05$ was considered statistically significant. All statistical analyses were conducted using SPSS for Windows version 14 (SPSS Inc., Chicago, IL, USA) and MedCalc for Windows version 4.2 (MedCalc Software, Mariakerke, Belgium).

\section{Results}

\section{Patient profiles}

A total of $786 \mathrm{HCC}$ patients who underwent locoregional therapy during the period of April 2002 to June 2008 were enrolled and formed the basis of this study. The baseline demographics of the study patients were shown in Table 1. Patients were predominantly elderly (mean age, 67 years) males (73\%). Among them, 50\% had evidence of chronic HBV infection and 34\% had evidence of chronic HCV infection. The baseline MELD score was $9.3 \pm 3.1$, and $81 \%$ of the patients had a well-preserved liver function (CTP class A). Five hundred (64\%) patients had a single tumor nodule, and $72 \%$ of patients had a maximal tumor size of $5 \mathrm{~cm}$ or smaller. The mean and median TTV was $177 \mathrm{~cm}^{3}$ (range, $0.1-3,591 \mathrm{~cm}^{3}$ ) and 21 $\mathrm{cm}^{3}$, respectively. Analysis of the distribution of TTV showed that $38 \%, 29 \%, 15 \%, 7 \%$ and $11 \%$ of patients had a TTV of $<10 \mathrm{~cm}^{3}, 10-50 \mathrm{~cm}^{3}, 50-200 \mathrm{~cm}^{3}, 200-500 \mathrm{~cm}^{3}$ and $>500 \mathrm{~cm}^{3}$, respectively. Of all patients, $60 \%$ had undergone TACE, $28 \%$ had undergone RFA and $10 \%$ had received PAI or PEI as the primary anti-cancer treatment.

Distribution and association of TTV and number and size of tumor nodule

The size and number of tumor nodule in relation to TTV were evaluated and shown in Table 2. For patients

\section{Table 1 Baseline demographics}

\begin{tabular}{lc}
\hline Number of patients & 786 \\
Age (mean \pm SD years; range) & $67 \pm 12(27-92)$ \\
Male/female (\%) & $73 / 27$ \\
Underlying liver disease (\%) & \\
HBsAg-positive & $393(50)$ \\
HBsAg-negative & \\
$\quad$ Anti-HCV-positive & $265(34)$ \\
$\quad$ Anti-HCV-negative & $128(16)$ \\
& \\
Tumoral characteristics (\%) & \\
Single lesion & $500(64)$ \\
Multi-nodular lesions & $286(36)$ \\
Maximal tumor diameter & \\
$\quad \leq 5 \mathrm{~cm}$ & $566(72)$ \\
$>5 \mathrm{~cm}$ & $220(28)$
\end{tabular}

Ascites (\%)

Yes

101 (13)

No

$685(87)$

Serum AFP level (ng/mL) (\%)

Median (range)

$<20$

$29(2-10,032,600)$

344 (44)

$20-400$

$288(37)$

$>400$

$154(19)$

Performance status (\%)

ECOG scale 0

$590(75)$

ECOG scale 1-3

$196(25)$

Serum biochemistries (mean \pm SD)

Albumin $(\mathrm{g} / \mathrm{dL})$

Bilirubin (mg/dL)

Creatinine (mg/dL)

Prothrombin time INR

ALT (IU/L)

AST (IU/L)

$3.7 \pm 0.6$

$1.1 \pm 1.0$

$1.3 \pm 3.2$

$1.1 \pm 0.3$

$69 \pm 68$

$52 \pm 44$

Child-Pugh-Turcotte class (\%)

A

639 (81)

B

147 (19)

MELD score (mean $\pm \mathrm{SD}$; range) (\%)

$<8$

$9.3 \pm 3.1(6.4-23.9)$

$336(43)$

215 (27)

235 (30)

Vascular invasion (\%)

No

$699(9)$

Yes 
Table 1 Baseline demographics (Continued)

\begin{tabular}{|c|c|}
\hline \multicolumn{2}{|l|}{ CLIP staging (\%) } \\
\hline Score 0 & $266(34)$ \\
\hline Score 1 & $276(35)$ \\
\hline Score 2 & $141(18)$ \\
\hline Score 3 & $66(8)$ \\
\hline Score 4 or 5 & $37(5)$ \\
\hline \multicolumn{2}{|l|}{ Total tumor volume $\left(\mathrm{cm}^{3}\right)(\%)$} \\
\hline Mean \pm SD (range) & $177 \pm 436(0.1-3,591)$ \\
\hline Median & 21 \\
\hline$<10$ & $297(38)$ \\
\hline $10-50$ & $226(29)$ \\
\hline $50-200$ & $121(15)$ \\
\hline $200-500$ & $57(7)$ \\
\hline$>500$ & $85(11)$ \\
\hline \multicolumn{2}{|l|}{ Treatment (\%) } \\
\hline PAI or PEI & $79(10)$ \\
\hline RFA & $221(28)$ \\
\hline TACE & $471(60)$ \\
\hline More than one methods & $15(2)$ \\
\hline
\end{tabular}

with uni-nodular or multi-nodular lesions, the TTV significantly increased with increasing maximal tumor diameter in the categories of $<3 \mathrm{~cm}, 3-6 \mathrm{~cm}$ and $>6 \mathrm{~cm}$ $(\mathrm{p}<0.0001)$. For the category of patients with maximal tumor diameter $<3 \mathrm{~cm}$, the TTV tended to significantly increase with the number of tumor nodules $(p<$ 0.0001 ). However, there were no significant differences of the TTV among the four groups (one, two, three and four or more nodules) of patients with maximal diameter of $3-6 \mathrm{~cm}(\mathrm{p}=0.054)$ and $6 \mathrm{~cm}(\mathrm{p}=0.177)$.

\section{Association of TTV and tumoral and cirrhosis parameters}

To determine the association between TTV and other important prognostic indicators of HCC, the relationship of TTV and serum AFP level, vascular invasion, CTP and MELD score was investigated (Figure 1). TTV significantly increased with increasing serum AFP levels ( $\mathrm{p}<$ $0.0001)$. TTV was also significantly higher in patients with vascular invasion $\left(624 \pm 774 \mathrm{~cm}^{3}\right)$ than patients without vascular invasion $\left(122 \pm 334 \mathrm{~cm}^{3}\right.$; $\left.\mathrm{p}<0.0001\right)$. However, there was no significant association between TTV and the MELD $(\mathrm{p}=0.21)$ or CTP $(\mathrm{p}=0.412)$ score. A total of 122 patients had a biopsy to evaluate tumor histology: 39, 69 and 14 patients had well-, moderateand poorly-differentiated HCC respectively; there was no significant difference among the grade of cell differentiation and TTV (mean values: $89 \pm 288,94 \pm 235$ and 166 $\pm 403 \mathrm{~cm}^{3}$ respectively, $\mathrm{p}=0.184$ ).
Table 2 Distribution of the number and size of tumor and total tumor volume

\begin{tabular}{|c|c|c|c|c|}
\hline \multirow{2}{*}{$\begin{array}{l}\text { No. of tumors and } \\
\text { patients, and total } \\
\text { tumor volume }\left(\mathrm{cm}^{3}\right)\end{array}$} & \multicolumn{3}{|c|}{ Maximal tumor diameter $(\mathrm{cm})$} & \multirow[t]{2}{*}{$p$} \\
\hline & $<3$ & $3-6$ & $>6$ & \\
\hline \multicolumn{5}{|l|}{ One nodule } \\
\hline No. of patients & 238 & 148 & 114 & \\
\hline $\begin{array}{l}\text { Total tumor volume } \\
\text { (median) }\end{array}$ & $\begin{array}{c}5 \pm 4 \\
(4)\end{array}$ & $\begin{array}{c}44 \pm 29 \\
(34)\end{array}$ & $\begin{array}{c}730 \pm 692 \\
(524)\end{array}$ & $<0.001^{\mathrm{a}}$ \\
\hline \multicolumn{5}{|l|}{ Two nodules } \\
\hline No. of patients & 73 & 45 & 32 & \\
\hline $\begin{array}{l}\text { Total tumor volume } \\
\text { (median) }\end{array}$ & $\begin{array}{l}7 \pm 5^{d} \\
(6)\end{array}$ & $\begin{array}{c}53 \pm 29 \\
(51)\end{array}$ & $\begin{array}{c}720 \pm 746 \\
(372)\end{array}$ & $<0.001^{\mathrm{b}}$ \\
\hline \multicolumn{5}{|l|}{ Three nodules } \\
\hline No. of patients & 34 & 22 & 10 & \\
\hline $\begin{array}{l}\text { Total tumor volume } \\
\text { (median) }\end{array}$ & $\begin{array}{c}7 \pm 5^{e} \\
(6)\end{array}$ & $\begin{array}{c}45 \pm 29 \\
(33)\end{array}$ & $\begin{array}{c}472 \pm 429 \\
(278)\end{array}$ & $<0.001^{c}$ \\
\hline \multicolumn{5}{|l|}{ Four or more nodules } \\
\hline No. of patients & 34 & 21 & 15 & \\
\hline $\begin{array}{l}\text { Total tumor volume } \\
\text { (median) }\end{array}$ & $\begin{array}{c}10 \pm 6^{f} \\
(11)\end{array}$ & $\begin{array}{c}59 \pm 41 \\
(66)\end{array}$ & $\begin{array}{c}937 \pm 719 \\
(703)\end{array}$ & \\
\hline$p$ & $<0.001$ & 0.054 & 0.177 & \\
\hline
\end{tabular}

Kruskal-Wallis test with post-test: $a, b$ and $c: p$ values all $<0.05$ for pairwise comparison between the 3 groups; $d$ vs e, $d$ vs $f$ and e vs $f: p$ values all $>0.05$.

\section{Survival analysis}

Up until July 2008, 216 (27\%) patients died during a mean follow-up period of $18 \pm 14$ months (range, 1-66 months). In the univariate survival analysis, ascites ( $\mathrm{p}<$ $0.001)$, ECOG performance status $(\mathrm{p}<0.001)$, vascular invasion $(\mathrm{p}<0.001)$, AFP level $(\mathrm{p}<0.001)$, MELD score $(\mathrm{p}=0.04)$, CTP score $(\mathrm{p}<0.001)$, AST level $(\mathrm{p}=0.001)$ and TTV $(\mathrm{p}<0.001)$ were significant prognostic predictors (Table 3). In the Cox proportional hazards model, CTP score of 6 or higher (RR: 1.67, p < 0.001), ECOG status 1 or higher (RR: $2.20, \mathrm{p}<0.001$ ), vascular invasion (RR: 2.14, $\mathrm{p}<0.001$ ), AFP level $>100 \mathrm{ng} / \mathrm{mL}$ (RR: $1.50, \mathrm{p}=0.006$ ) were significant independent prognostic factors predicting a poor survival (Table 4). In addition, there was an increasing trend of mortality risk across a gradient of TTV in the Cox model. Compared with patients with TTV $<10 \mathrm{~cm}^{3}$, the adjusted relative risk for mortality was 1.13 (95\% CI: $0.78-1.65, \mathrm{p}=0.514)$ for patients with TTV 10-50 $\mathrm{cm}^{3}$; 1.74 (95\% CI: $1.15-2.64$, $\mathrm{p}=0.009)$ for patients with TTV $50-200 \mathrm{~cm}^{3} ; 2.15(95 \%$ CI: $1.24-3.72, \mathrm{p}=0.006)$ for patients with $200-500 \mathrm{~cm}^{3}$; 3.92 (95\% CI: 2.55-6.03, p < 0.001) for patients with TTV $>500 \mathrm{~cm}^{3}$. The comparison of the survival rates among the five categories of TTV was shown in Figure 2. 
A

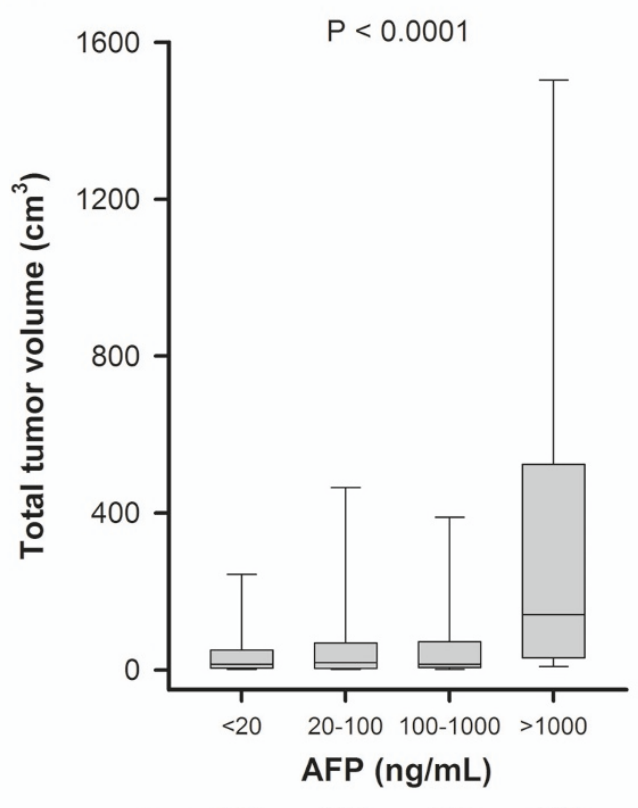

$n=\begin{array}{llll}344 & 187 & 143 & 112\end{array}$

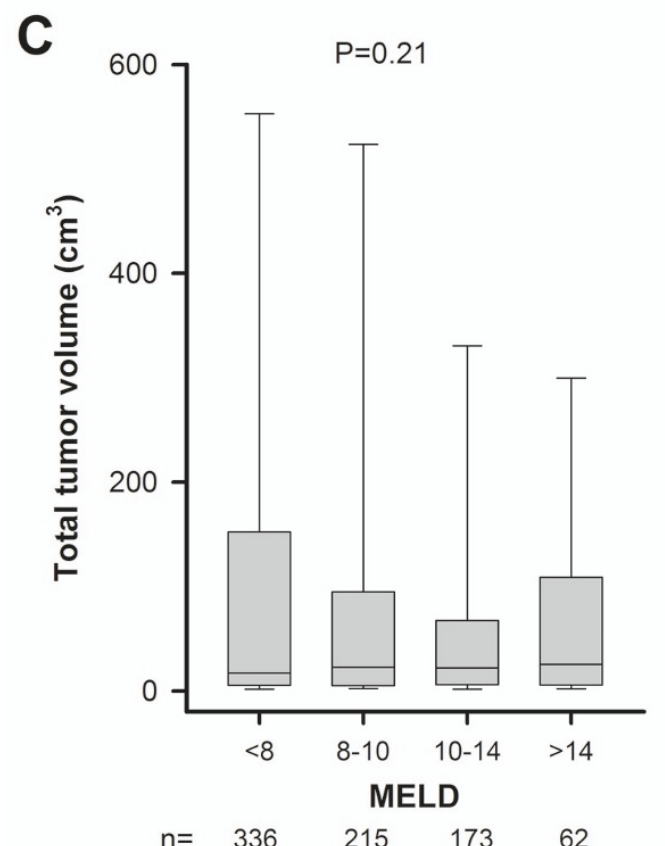

B
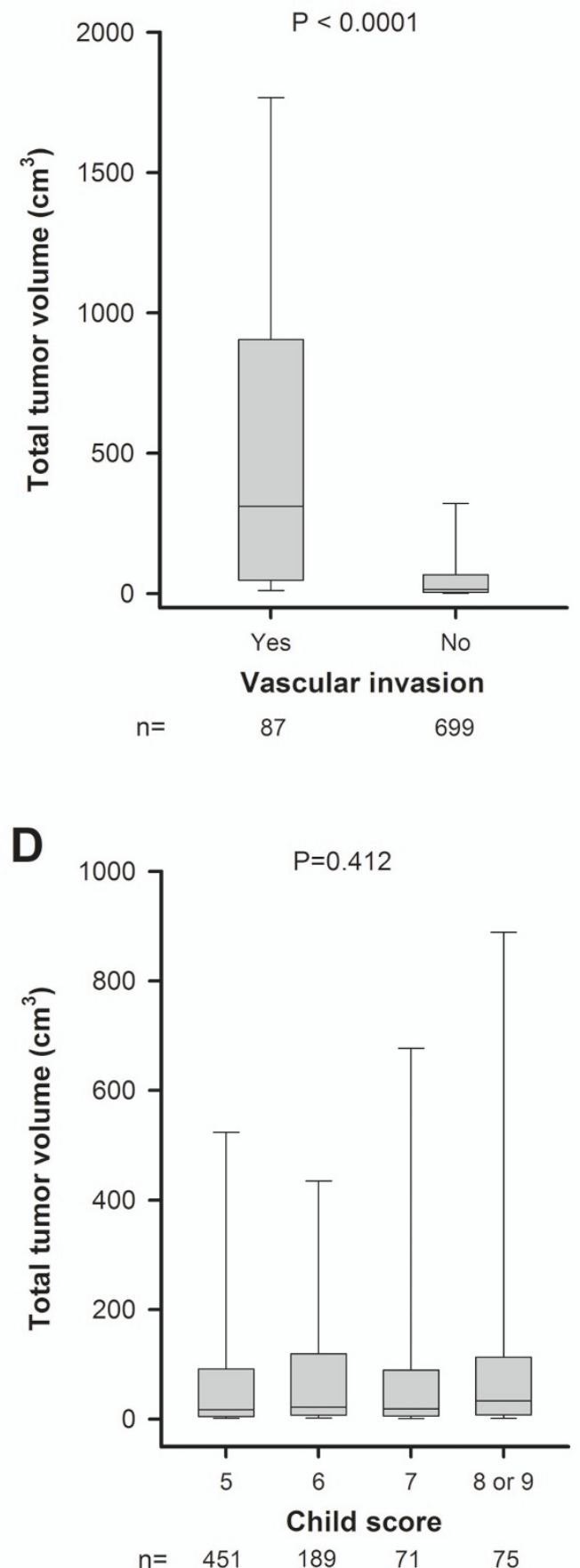

Figure 1 Association of the total tumor volume (TTV) with serum AFP level (panel A), vascular invasion (panel B), MELD (panel C) and Child score (panel D). AFP level and vascular invasion, but not MELD and Child score, were significantly associated with TTV. Data were expressed as median (horizontal bars) and 25\% to 75\% percentile of the distribution (lower and upper margin of the square); the upper and lower vertical bars indicate $90 \%$ and $10 \%$ percentile of the distribution, respectively. 
Table 3 Significance of the prognostic predictors in the univariate survival analysis

\begin{tabular}{|c|c|c|c|c|}
\hline \multirow[t]{2}{*}{ Parameters } & \multirow[t]{2}{*}{ No. of patients } & \multicolumn{2}{|c|}{ Survival rate (\%) } & \multirow[t]{2}{*}{$p$} \\
\hline & & $2-y r$ & $4-y r$ & \\
\hline Age (years) & & & & 0.795 \\
\hline$>60$ & 554 & 68 & 39 & \\
\hline$\leq 60$ & 232 & 70 & 37 & \\
\hline Gender & & & & 0.713 \\
\hline Male & 576 & 69 & 42 & \\
\hline Female & 210 & 71 & 29 & \\
\hline $\mathrm{HBsAg}$ & & & & 0.589 \\
\hline Positive & 393 & 68 & 42 & \\
\hline Negative & 393 & 70 & 34 & \\
\hline Ascites & & & & $<0.001$ \\
\hline Yes & 101 & 50 & 11 & \\
\hline No & 685 & 72 & 42 & \\
\hline Performance status & & & & $<0.001$ \\
\hline ECOG 0 & 590 & 75 & 45 & \\
\hline ECOG 1 or higher & 196 & 51 & 10 & \\
\hline Vascular invasion & & & & $<0.001$ \\
\hline Yes & 87 & 35 & 22 & \\
\hline No & 699 & 72 & 41 & \\
\hline AFP $(\mathrm{ng} / \mathrm{mL})$ & & & & $<0.001$ \\
\hline$>100$ & 253 & 58 & 33 & \\
\hline$<100$ & 533 & 74 & 42 & \\
\hline MELD score & & & & 0.04 \\
\hline$>10$ & 234 & 62 & 36 & \\
\hline$<10$ & 552 & 72 & 40 & \\
\hline CTP score & & & & $<0.001$ \\
\hline 5 & 451 & 75 & 50 & \\
\hline 6 or higher & 335 & 60 & 25 & \\
\hline $\mathrm{ALT}(\mathrm{IU} / \mathrm{L})$ & & & & 0.934 \\
\hline$>40$ & 499 & 70 & 38 & \\
\hline$\leq 40$ & 287 & 67 & 40 & \\
\hline AST (IU/L) & & & & 0.001 \\
\hline$>40$ & 551 & 65 & 31 & \\
\hline$\leq 40$ & 235 & 77 & 52 & \\
\hline Total tumor volume $\left(\mathrm{cm}^{3}\right)$ & & & & $<0.001$ \\
\hline$<10$ & 297 & 80 & 48 & \\
\hline $10-50$ & 226 & 74 & 47 & \\
\hline $50-200$ & 121 & 56 & 25 & \\
\hline $200-500$ & 57 & 54 & - & \\
\hline$>500$ & 85 & 34 & 10 & \\
\hline
\end{tabular}

Patients with the largest TTV had the highest cumulative mortality rate, whereas patients with the smallest TTV tended to have a better survival rate $(\mathrm{p}<0.001)$.

\section{Application of TTV in the staging system}

To further investigate the feasibility of TTV in the cancer staging system, we have replaced the factor of tumor character in the CLIP scoring system with TTV $(<50$ $\mathrm{cm}^{3}, 50-200 \mathrm{~cm}^{3}, 200-500 \mathrm{~cm}^{3}$ and $>500 \mathrm{~cm}^{3}$; Table 5). The modified CLIP system used a TTV-based scoring method to re-stage all study patients. The mean scores in the original and modified CLIP system were $1.2 \pm 1.2$ (range, 0-5) and $1.2 \pm 1.5$ (range, 0-7), respectively. In the survival analysis, there was a significant difference in the survival distribution across different score groups in the original $(\mathrm{p}<0.001$; Figure $3 \mathrm{~A})$ and TTV-based $(\mathrm{p}<$ 0.001; Figure 3B) CLIP scoring system. The survival significantly tended to be worse with increasing scores in both models. The modified CLIP system had a lower AIC value (3875.7) in comparison with the original CLIP model (3969.6), suggesting a better predictive accuracy for the TTV-based model.

\section{Discussion}

In this study, we have proposed a new prognostic predictor, the TTV, for HCC, and have evaluated its feasibility for outcome prediction. In most published literatures, the traditional way to report the tumor burden of HCC is to describe the size and number of tumor nodule simultaneously. However, it could be quite difficult or even confusing to assess the prognosis of patients with a wide range of number and size of tumor nodules. To solve this problem, the factors of number and size of tumor nodule are transformed into one single parameter in this study. There are several clear advantages of this strategy. Firstly, the TTV represents true tumor burden and can simplify the way to describe the extent of tumor involvement in liver. Secondly, TTV is a continuous variable that can be easily calculated and used to predict the survival more specifically. Alternatively, it can also be categorized into different risk groups in terms of outcome prediction. Thirdly, TTV can be incorporated into the staging system for HCC because there was a significant dose-response relationship between the TTV and long-term mortality risk in our study. Notably, patients with TTV 50-200 $\mathrm{cm}^{3}, 200-500 \mathrm{~cm}^{3}$ and $>500 \mathrm{~cm}^{3}$ had a significantly increased mortality risk of $74 \%, 115 \%$ and $292 \%$, respectively, in comparison to patients with TTV $<10 \mathrm{~cm}^{3}$ after adjusting for other significant prognostic variables in the Cox analysis. These results indicate that TTV can serve as an independent prognostic predictor for HCC.

In the five risk-stratified TTV groups, we found that patients with TTV $<50 \mathrm{~cm}^{3}$ had a lower mortality risk and patients with TTV $>200 \mathrm{~cm}^{3}$ had an increased 
Table 4 Adjusted relative risks of the prognostic predictors in the Cox proportional hazards model

\begin{tabular}{|c|c|c|c|c|c|}
\hline Predictors & Regression coefficient & Standard error & Relative risk & $95 \% \mathrm{Cl}$ & $\mathrm{p}$ \\
\hline Child score $\geq 6$ & 0.51 & 0.15 & 1.67 & $1.25-2.23$ & $<0.001$ \\
\hline ECOG scale $\geq 1$ & 0.79 & 0.15 & 2.20 & $1.63-2.97$ & $<0.001$ \\
\hline Vascular invasion & 0.76 & 0.20 & 2.14 & $1.44-3.19$ & $<0.001$ \\
\hline AFP $>100 \mathrm{ng} / \mathrm{mL}$ & 0.40 & 0.15 & 1.50 & $1.13-1.99$ & 0.006 \\
\hline \multicolumn{6}{|l|}{ Total tumor volume } \\
\hline$<10 \mathrm{~cm}^{3}$ & - & - & 1 & - & - \\
\hline $10-50 \mathrm{~cm}^{3}$ & 0.13 & 0.19 & 1.13 & $0.78-1.65$ & 0.514 \\
\hline $50-200 \mathrm{~cm}^{3}$ & 0.55 & 0.21 & 1.74 & $1.15-2.64$ & 0.009 \\
\hline $200-500 \mathrm{~cm}^{3}$ & 0.77 & 0.28 & 2.15 & $1.24-3.72$ & 0.006 \\
\hline$>500 \mathrm{~cm}^{3}$ & 1.37 & 0.22 & 3.92 & $2.55-6.03$ & $<0.001$ \\
\hline
\end{tabular}

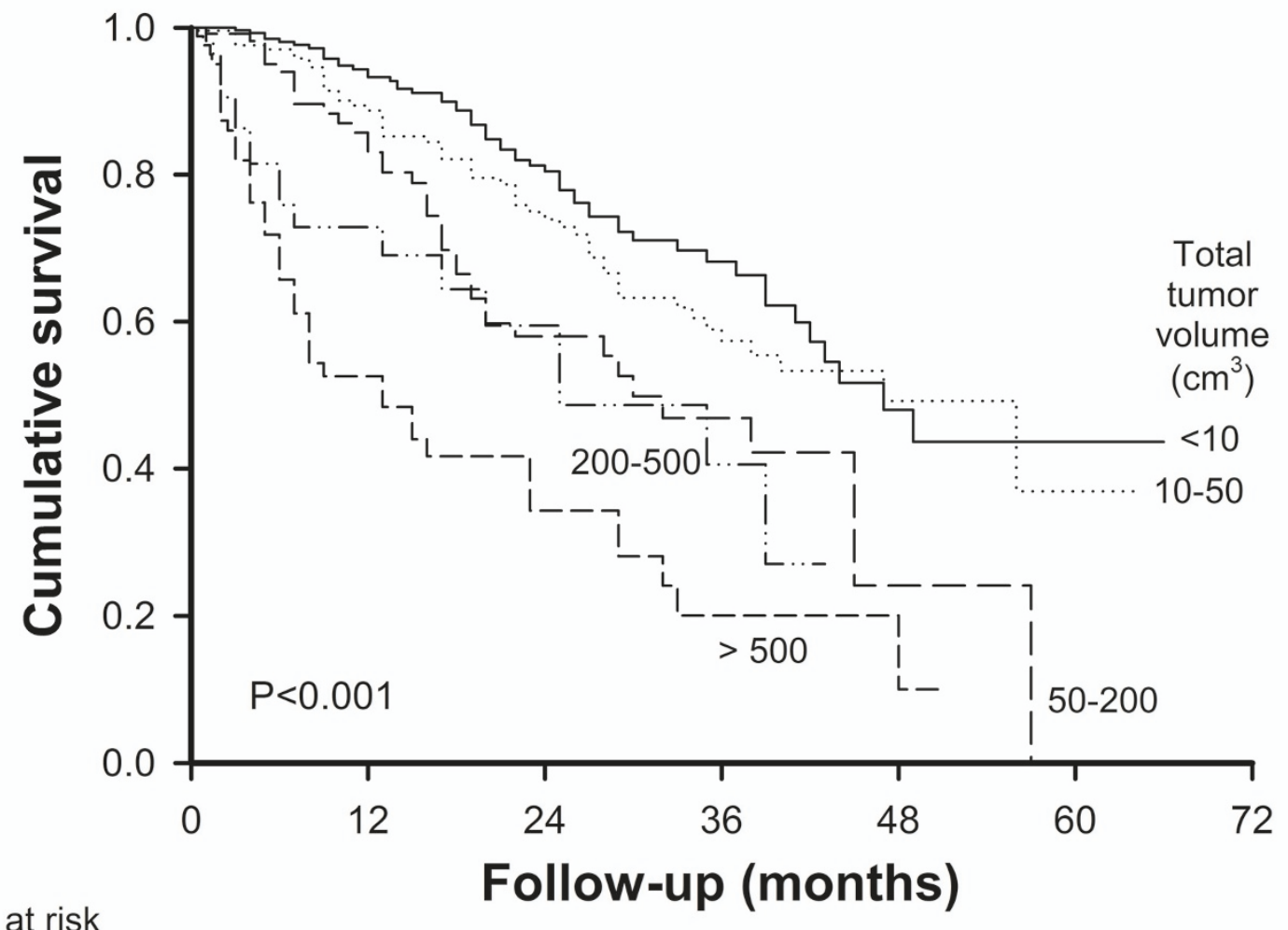

No. at risk

$\begin{array}{rrrrr}<10 & 297 & 178 & 95 & 38 \\ 10-50 & 226 & 126 & 72 & 34 \\ 50-200 & 121 & 61 & 26 & 11 \\ 200-500 & 57 & 19 & 11 & 4 \\ >500 & 85 & 25 & 13 & 4\end{array}$

$\begin{array}{rr}11 & 1 \\ 9 & 2 \\ 2 & 3 \\ 0 & \\ 1 & 0\end{array}$

Figure 2 Comparison of the survival rates between five groups of patients with different total tumor volumes. 
Table 5 Risk score assessment according to the original and total tumor volume (TTV)-based CLIP scoring system

\begin{tabular}{|c|c|c|}
\hline Parameters & Original CLIP & TTV-based CLIP \\
\hline \multicolumn{3}{|l|}{ Tumor morphology } \\
\hline Single and $<50 \%$ liver span & 0 & - \\
\hline Multiple and $<50 \%$ liver span & 1 & - \\
\hline$\geq 50 \%$ liver span & 2 & - \\
\hline \multicolumn{3}{|l|}{ Total tumor volume } \\
\hline$<50 \mathrm{~cm}^{3}$ & - & 0 \\
\hline $50-200 \mathrm{~cm}^{3}$ & - & 1 \\
\hline $200-500 \mathrm{~cm}^{3}$ & - & 2 \\
\hline$>500 \mathrm{~cm}^{3}$ & - & 3 \\
\hline \multicolumn{3}{|l|}{ Serum AFP level (ng/mL) } \\
\hline$<400$ & 0 & 0 \\
\hline$\geq 400$ & 1 & 1 \\
\hline \multicolumn{3}{|l|}{ Macroscopic vascular invasion } \\
\hline No & 0 & 0 \\
\hline Yes & 1 & 1 \\
\hline \multicolumn{3}{|l|}{ CTP class } \\
\hline A & 0 & 0 \\
\hline B & 1 & 1 \\
\hline C & 2 & 2 \\
\hline
\end{tabular}

The score range is 0-6 for the original CLIP and 0-7 for TTV-based CLIP scoring system.

mortality risk; the risk for patients with TTV between 50 to $200 \mathrm{~cm}^{3}$ was considered intermediate. A TTV of $50 \mathrm{~cm}^{3}$ is equivalent to a single tumor nodule with a diameter of $4.6 \mathrm{~cm}$. This cutoff is considered appropriate for clinical application because TTV $<50 \mathrm{~cm}^{3}$ is within the Milan criteria, suggesting the risk of tumor recurrence is very low after liver transplantation or partial hepatectomy $[9,27]$. On the other hand, a TTV of $200 \mathrm{~cm}^{3}$ is equivalent to a single tumor nodule with a diameter of $7.3 \mathrm{~cm}$ or three nodules the diameter in each of which being $5 \mathrm{~cm}$. Patients with TTV more than $200 \mathrm{~cm}^{3}$ belong to a relatively advanced cancer stage that is beyond the University of California at San Francisco criteria for liver transplantation $[28,29]$. Although selecting a cutoff to define the mortality risk may be arbitrary in patients undergoing different therapeutic strategies, these two cutoffs of TTV may be used for future reference in prognostic prediction.

The role and clinical significance of using TTV as a prognostic predictor were validated in the staging system for HCC. The CLIP scoring system is a widely used model for prognostic stratification $[8,30]$. We found that using TTV in the CLIP system could accurately predict the outcome of patients in different score groups (Figure 3).
This result suggests that TTV is a feasible alternative indicator of tumor burden for cancer staging.

An important implication of this study is that patients with multi-nodular lesions may not necessarily have a larger TTV (Table 2). This is because many patients had a main tumor and several satellite lesions which could be quite small. As a result, the calculated TTV in patients with more tumor nodules was not necessarily larger than that of patients with fewer number of tumor nodules. This finding implicates that by reporting the size and number of tumor nodule in HCC patients may not be sufficient and sometimes could be misleading if the actual tumor size for individual tumor nodule is not mentioned. In this regard, reporting the value of TTV instead of the size and number of tumor nodule may more accurately indicate the extent of tumor involvement in liver.

TTV was also closely linked with serum AFP level and the presence of vascular invasion. Both of these two factors are important tumor-associated parameters and were also independent prognostic predictors in our analysis. Abundant studies consistently showed that these two predictors may predict the survival of HCC patients undergoing either surgical or non-surgical therapy [31-39]. Since TTV can be used to reflect the status of tumor burden, it is not surprising that a larger TTV is expected to be more often associated with a higher AFP level and vascular invasion. By contrast, it is anticipated that TTV is not related to the severity of liver cirrhosis, as indicated by the MELD and CTP score, in this study. These findings suggest that TTV is an authentic tumoral factor independent of the severity of liver cirrhosis.

In addition to serum AFP level, vascular invasion and TTV, a higher CTP score and performance status were also identified as independent prognostic predictors in this study. A higher CTP score is known to correlate with the severity of liver cirrhosis and could independently predict the mortality risk. Performance status represents the overall physical reserve in a given patient. This parameter has been exclusively included in the BCLC system which was suggested as the primary staging system for HCC [40], and our findings further confirm its role for prognostic prediction.

There are nevertheless a few potential limitations of this study. Firstly, a shortcoming of using TTV is that the estimation of tumor volume is based on the assumption that all tumors are spherical. This estimate might be erroneous if the tumor is irregular shaped. Secondly, our results were derived from patients undergoing locoregional therapy, therefore the strategy for selecting appropriate cutoffs of TTV for patients receiving other treatment modalities may not be the same. Thirdly, the treatments used in individual patient were heterogeneous depending on the status of tumor spread and 

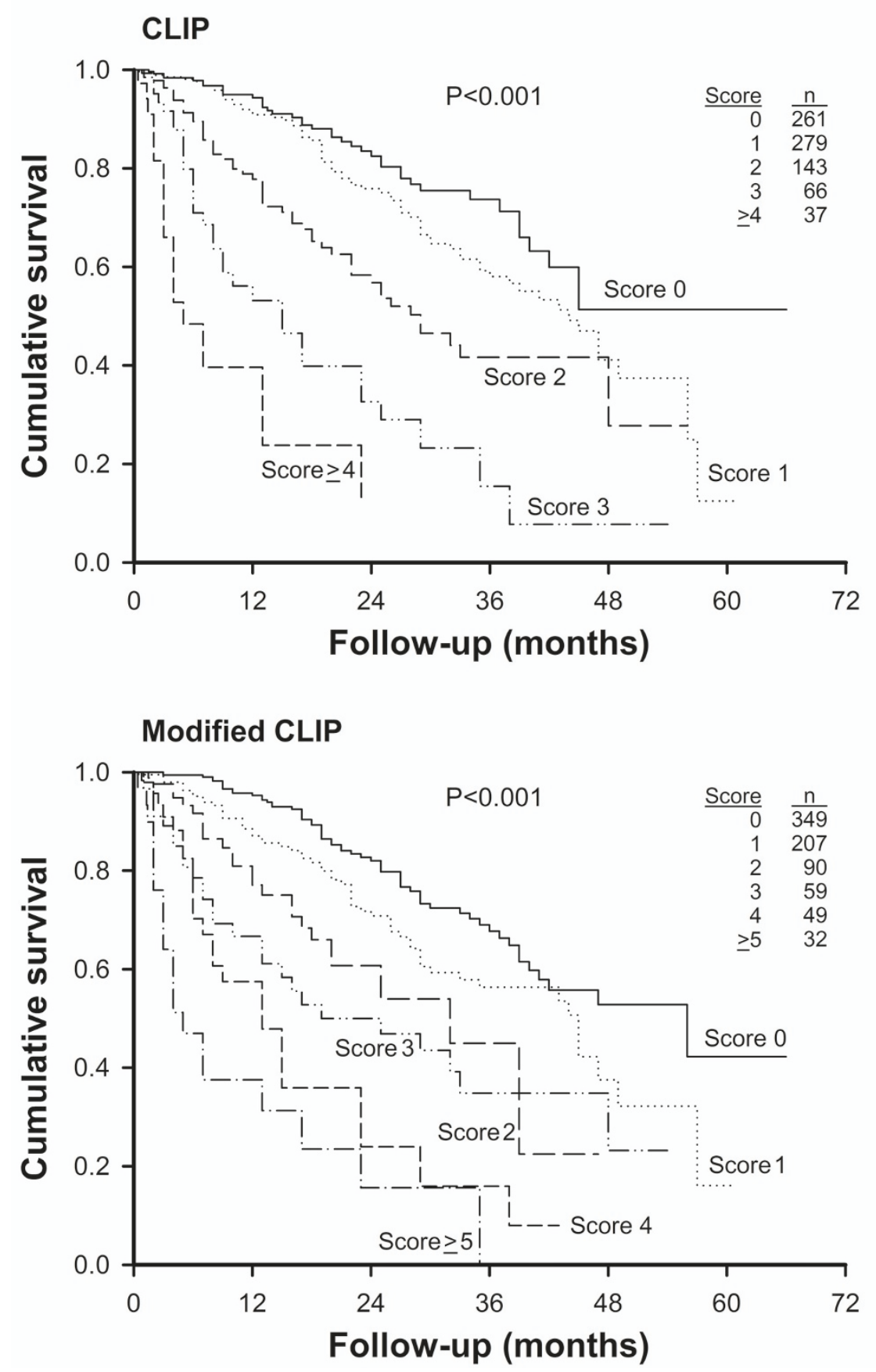

Figure 3 Comparison of the survival distributions between different score groups in the original and modified CLIP systems. There was a significant difference in the survival distribution across all score groups in the original $(p<0.001$; panel A) and TTV-based ( $p<0.001$; panel B) CLIP scoring system. The survival significantly tended to be worse with increasing scores in both models.

severity of cirrhosis. This may interfere with the assessment of the impact of TTV on survival. Lastly, the TTV in HCC patients with extrahepatic metastasis was not considered in this study. The role of TTV as a prognostic predictor in these far-advanced cancer stage patients needs further studies to clarify.

\section{Conclusions}

Our results indicate that TTV is a feasible prognostic predictor across a wide range of gradient and can be used to predict the mortality risk in HCC patients undergoing locoregional therapy. TTV can be easily and readily obtained, and future clinical trials of HCC may 
include this parameter for mortality risk stratification. Selecting appropriate cutoffs of TTV may help refine the design of cancer staging system and fine-tuning of treatment planning.

\begin{abstract}
Abbreviations
AFP: $\alpha$-fetoprotein; (AIC): Akaike information criterion; ALT: alanine aminotransferase; AST: aspartate aminotransferase; Cl: confidence interval; CLIP: Cancer of the Liver Italian Program; CTP: Child-Turcotte-Pugh; ECOG Eastern Cooperative Oncology Group; HBV: hepatitis B virus; HCV: hepatitis C virus; HCC: hepatocellular carcinoma; INR: international normalized ratio; MELD: model for end-stage liver disease; PAl: percutaneous acetic acid injection; PEl: percutaneous ethanol injection; RFA: radiofrequency ablation; RR: relative risk: SD: standard deviation; TACE: transarterial chemoembolization; TTV: total tumor volume
\end{abstract}

\section{Acknowledgements}

This study was supported by a grant (V99C1-169) from Taipei Veterans General Hospital, Taipei, Taiwan, a grant (DOH99-TD-C-111-007) from the Center of Excellence for Cancer Research at Taipei Veterans General Hospital, Taiwan, and a grant (RD-2010-013) from National Yang-Ming University Hospital, Yilan, Taiwan.

\section{Author details}

'Institute of Pharmacology, National Yang-Ming University School of Medicine, Taipei, Taiwan. ${ }^{2}$ Institute of Clinical Medicine, National Yang-Ming University School of Medicine, Taipei, Taiwan. ${ }^{3}$ Faculty of Medicine, National Yang-Ming University School of Medicine, Taipei, Taiwan. ${ }^{4}$ Department of Medicine, Taipei Veterans General Hospital, Taipei, Taiwan. ${ }^{5}$ Department of Radiology, Taipei Veterans General Hospital, Taipei, Taiwan. ${ }^{6}$ Department of Medicine, National Yang-Ming University Hospital, Yilan, Taiwan.

\section{Authors' contributions}

Data acquisition and analysis, and manuscript preparation were performed by $\mathrm{TH}, \mathrm{CYH}$ and $\mathrm{YHH}$. Patient enrollment, treatment and follow-up were performed by HCL, CWS, RCL, JHC and YYC. PCL was responsible for study design and statistical analysis. Critical manuscript review was performed by

SDL. All authors have read and approved the final manuscript.

\section{Competing interests}

The authors declare that they have no competing interests.

Received: 4 March 2010 Accepted: 31 December 2010

Published: 31 December 2010

\section{References}

1. El-Serag HB, Davila JA, Petersen NJ, McGlynn KA: The continuing increase in the incidence of hepatocellular carcinoma in the United States: an update. Ann Intern Med 2003, 139:817-23.

2. Pocobelli G, Cook LS, Brant R, Lee SS: Hepatocellular carcinoma incidence trends in Canada: analysis by birth cohort and period of diagnosis. Liver Int 2008, 28:1272-9.

3. Pompili M, Rapaccini GL, de Luca F, Caturelli E, Astone A, Siena DA, Villani MR, Grattagliano A, Cedrone A, Gasbarrini G: Risk factors for intrahepatic recurrence of hepatocellular carcinoma in cirrhotic patients treated by percutaneous ethanol injection. Cancer 1997, 79:1501-8.

4. Trevisani F, Magini G, Santi V, Morselli-Labate AM, Cantarini MC, Di Nolfo MA, Del Poggio P, Benvegnù L, Rapaccini G, Farinati F, Zoli M, Borzio F, Giannini EG, Caturelli E, Bernardi M: Impact of etiology of cirrhosis on the survival of patients diagnosed with hepatocellular carcinoma during surveillance. Am J Gastroenterol 2007, 102:1022-31.

5. Chen WT, Chau GY, Lui WY, Tsay SH, King KL, Loong CC, Wu CW: Recurrent hepatocellular carcinoma after hepatic resection: prognostic factors and long-term outcome. Eur J Surg Oncol 2004, 30:414-20.

6. Martins A, Cortez-Pinto H, Marques-Vidal P, Mendes N, Silva S, Fatela N, Glória H, Marinho R, Távora I, Ramalho F, de Moura MC: Treatment and prognostic factors in patients with hepatocellular carcinoma. Liver Int 2006, 26:680-7.
7. The Cancer of the Liver Italian Program (CLIP) investigators: Prospective validation of the CLIP score: a new prognostic system for patients with cirrhosis and hepatocellular carcinoma. Hepatology 2000, 31:840-5.

8. Mazzaferro V, Regalia E, Doci R, Andreola S, Pulvirenti A, Bozzetti F, Montalto F, Ammatuna M, Morabito A, Gennari L: Liver transplantation for the treatment of small hepatocellular carcinomas in patients with cirrhosis. N Engl J Med 1996, 334:693-9.

9. Yuen MF, Hou JL, Chutaputti A: Hepatocellular carcinoma in the Asia pacific region. J Gastroenterol Hepatol 2009, 24:346-53.

10. Kulik LM, Mulcahy MF, Omary RA, Salem R: Emerging approaches in hepatocellular carcinoma. J Clin Gastroenterol 2007, 41:839-54.

11. Lin SM, Lin CJ, Lin CC, Hsu CW, Chen YC: Radiofrequency ablation improves prognosis compared with ethanol injection for hepatocellular carcinoma $<$ or $=4 \mathrm{~cm}$. Gastroenterology 2004, 127:1714-23.

12. Huang GT, Lee PH, Tsang YM, Lai MY, Yang PM, Hu RH, Chen PJ, Kao JH, Sheu JC, Lee CZ, Chen DS: Percutaneous ethanol injection versus surgical resection for the treatment of small hepatocellular carcinoma: a prospective study. Ann Surg 2005, 242:36-42

13. Ercolani G, Grazi GL, Ravaioli M, Cescon M, Gardini A, Varotti G, Del Gaudio M, Nardo B, Cavallari A: Liver resection for multiple colorectal metastases: influence of parenchymal involvement and total tumor volume, vs number or location, on long-term survival. Arch Surg 2002, 137:1187-92.

14. Toso C, Asthana S, Bigam DL, Shapiro AM, Kneteman NM: Reassessing selection criteria prior to liver transplantation for hepatocellular carcinoma utilizing the Scientific Registry of Transplant Recipients database. Hepatology 2009, 49:832-8.

15. Bruix J, Sherman M: Management of hepatocellular carcinoma. Hepatology 2005, 42:1208-36.

16. Bruix J, Sherman M, Llovet JM, Beaugrand M, Lencioni R, Burroughs AK, Christensen E, Pagliaro L, Colombo M, Rodés J: Clinical management of hepatocellular carcinoma: Conclusions of the Barcelona-2000 EASL conference. J Hepatol 2001, 35:421-30.

17. Wiesner R, Edwards E, Freeman R, Harper A, Kim R, Kamath P, Kremers W, Lake J, Howard T, Merion RM, Wolfe RA, Krom R: Model for end-stage liver disease (MELD) and allocation of donor livers. Gastroenterology 2003, 124:91-6.

18. Huo TI, Lin HC, Hsia CY, Wu JC, Lee PC, Chi CW, Lee SD: The model for end-stage liver disease based cancer staging systems are better prognostic models for hepatocellular carcinoma: a prospective sequential survey. Am J Gastroenterol 2007, 102:1920-30.

19. Huo TI, Lee SD, Lin HC: Selecting an optimal prognostic system for liver cirrhosis: the model for end-stage liver disease and beyond. Liver Int 2008, 28:606-13.

20. Huo TI, Lin HC, Wu JC, Lee FY, Hou MC, Lee PC, Chang FY, Lee SD: Proposal of a modified Child-Turcotte-Pugh scoring system and comparison with the model for end-stage liver disease for outcome prediction in patients with cirrhosis. Liver Transp/ 2006, 12:65-71.

21. Huo Tl, Lee PC, Huang YH, Wu JC, Lin HC, Chiang JH, Lee SD: The sequential changes of the model for end-stage liver disease score correlate with the severity of liver cirrhosis in patients with hepatocellular carcinoma undergoing locoregional therapy. J Clin Gastroenterol 2006, 40:543-50.

22. Huo Tl, Huang YH, Lin HC, Wu JC, Chiang JH, Lee PC, Chang FY, Lee SD: Proposal of a modified Cancer of the Liver Italian Program staging system based on the model for end-stage liver disease for patients with hepatocellular carcinoma undergoing loco-regional therapy. Am J Gastroenterol 2006, 101:975-82.

23. Huo TI, Huang YH, Wu JC, Lee PC, Chang FY, Lee SD: Induction of complete tumor necrosis may reduce intrahepatic metastasis and prolong survival in patients with hepatocellular carcinoma undergoing locoregional therapy: a prospective study. Ann Oncol 2004, 15:775-80.

24. Hosmer DW, Hosmer T, Le Cessie S, Lemeshow S: A comparison of goodness-of-fit tests for the logistic regression model. Stat Med 1997, 16:965-80

25. Feinsten AR: Clinical biostatistics XVI. The process of prognostic stratification. Clin Pharmacol Ther 1972, 13:609-24.

26. Foster MR: Key concepts in model selection: Performance and generalizability. J Math Psychol 2000, 44:205-31.

27. Yeh CN, Chen MF, Lee WC, Jeng LB: Prognostic factors of hepatic resection for hepatocellular carcinoma with cirrhosis: univariate and multivariate analysis. J Surg Oncol 2002, 81:195-202. 
28. Yao F, Ferrell L, Bass N, Watson JJ, Bacchetti P, Venook A, Ascher NL, Roberts JP: Liver transplantation for hepatocellular carcinomas: expansion of the tumor size limits does not adversely impact survival. Hepatology 2001, 33:1394-1403.

29. Decaens T, Roudot-Thoraval F, Hadni-Bresson S, Meyer C, Gugenheim J, Durand F, Bernard PH, Boillot O, Sulpice L, Calmus Y, Hardwigsen J, Ducerf C, Pageaux GP, Dharancy S, Chazouilleres O, Cherqui D, Duvoux C: Impact of UCSF criteria according to pre- and post-OLT tumor features: analysis of 479 patients listed for HCC with a short waiting time. Liver Transpl 2006, 12:1761-9.

30. Cho YK, Chung JW, Kim JK, Ahn YS, Kim MY, Park YO, Kim WT, Byun JH: Comparison of 7 staging systems for patients with hepatocellular carcinoma undergoing transarterial chemoembolization. Cancer 2008, 112:352-61.

31. Hsu CY, Hsia CY, Huang YH, Su CW, Lin HC, Lee PC, Loong CC, Chiang JH, Huo TI, Lee SD: Selecting an optimal staging system for hepatocellular carcinoma: comparison of 5 currently used prognostic models. Cancer 2010, 116:3006-14.

32. Hosaka T, Ikeda K, Kobayashi M, Hirakawa M, Kawamura Y, Yatsuji H, Sezaki H, Akuta N, Suzuki F, Suzuki Y, Saitoh S, Arase Y, Kumada H: Predictive factors of advanced recurrence after curative resection of small hepatocellular carcinoma. Liver Int 2009, 29:736-42.

33. Bouza C, López-Cuadrado T, Alcázar R, Saz-Parkinson Z, Amate JM: Metaanalysis of percutaneous radiofrequency ablation versus ethanol injection in hepatocellular carcinoma. BMC Gastroenterol 2009, 9:31.

34. Hsu CY, Huang YH, Hsia CY, Su CW, Lin HC, Loong CC, Chiou YY, Chiang JH, Lee PC, Huo TI, Lee SD: A new prognostic model for hepatocellular carcinoma based on total tumor volume: the Taipei Integrated Scoring System. J Hepatol 2010, 53:108-17.

35. Pompili M, Rapaccini GL, Covino M, Pignataro G, Caturelli E, Siena DA Villani MR, Cedrone A, Gasbarrini G: Prognostic factors for survival in patients with compensated cirrhosis and small hepatocellular carcinoma after percutaneous ethanol injection therapy. Cancer 2001, 92:126-35.

36. Huo TI, Huang YH, Wu JC: Percutaneous ablation therapy for hepatocellular carcinoma: current practice and future perspectives. $J$ Chin Med Assoc 2005, 68:155-9.

37. Tandon P, Garcia-Tsao G: Prognostic indicators in hepatocellular carcinoma: a systematic review of 72 studies. Liver Int 2009, 29:502-10.

38. Kirikoshi H, Saito S, Yoneda M, Fujita K, Mawatari H, Uchiyama T, Higurashi T, Imajo K, Sakaguchi T, Atsukawa K, Sawabe A, Kanesaki A, Takahashi H, Abe Y, Inamori M, Kobayashi N, Kubota K, Ueno N, Nakajima A: Outcomes and factors influencing survival in cirrhotic cases with spontaneous rupture of hepatocellular carcinoma: a multicenter study. BMC Gastroenterol 2009, 9:29.

39. Wu JC, Huang YH, Chau GY, Su CW, Lai CR, Lee PC, Huo TI, Sheen IJ, Lee SD, Lui WY: Risk factors for early and late recurrence in hepatitis B-related hepatocellular carcinoma. J Hepatol 2009, 51:890-7.

40. Llovet JM, Di Bisceglie AM, Bruix J, Kramer BS, Lencioni R, Zhu AX Sherman M, Schwartz M, Lotze M, Talwalkar J, Gores GJ: Design and endpoints of clinical trials in hepatocellular carcinoma. J Natl Cancer Inst 2008, 100:698-711.

\section{Pre-publication history}

The pre-publication history for this paper can be accessed here: http://www.biomedcentral.com/1471-230X/10/146/prepub

doi:10.1186/1471-230X-10-146

Cite this article as: Huo et al:: Prognostic prediction across a gradient of total tumor volume in patients with hepatocellular carcinoma undergoing locoregional therapy. BMC Gastroenterology 2010 10:146.

\section{Submit your next manuscript to BioMed Central and take full advantage of:}

- Convenient online submission

- Thorough peer review

- No space constraints or color figure charges

- Immediate publication on acceptance

- Inclusion in PubMed, CAS, Scopus and Google Scholar

- Research which is freely available for redistribution

Submit your manuscript at www.biomedcentral.com/submit
Biomed Central 